\title{
Virulence properties of Campylobacter jejuni isolates of poultry and human origin
}

\author{
Kim Van Deun, ${ }^{1}$ Freddy Haesebrouck, ${ }^{1}$ Marc Heyndrickx, ${ }^{2}$ \\ Herman Favoreel, ${ }^{3}$ Jeroen Dewulf, ${ }^{4}$ Liesbeth Ceelen, ${ }^{1}$ Linn Dumez, ${ }^{1}$ \\ Winy Messens, ${ }^{2}$ Saskia Leleu, ${ }^{2}$ Filip Van Immerseel, ${ }^{1}$ Richard Ducatelle ${ }^{1}$ \\ and Frank Pasmans ${ }^{1}$
}

Correspondence

Kim Van Deun

kim.vandeun@ugent.be

Received 16 April 2007

Accepted 25 June 2007

\author{
${ }^{1}$ Department of Pathology, Bacteriology and Avian Diseases, Ghent University, Salisburylaan 133, \\ 9820 Merelbeke, Belgium \\ ${ }^{2}$ Institute for Agricultural and Fisheries Research (ILVO), Technology and Food Unit, \\ Brusselsesteenweg 370, 9090 Melle, Belgium \\ ${ }^{3}$ Department of Virology, Parasitology and Immunology, Ghent University, Salisburylaan 133, \\ 9820 Merelbeke, Belgium \\ ${ }^{4}$ Department of Reproduction, Obstetrics and Herd Health, Ghent University, Salisburylaan 133, \\ 9820 Merelbeke, Belgium
}

\begin{abstract}
Campylobacter jejuni is one of the leading causes of food-borne gastroenteritis. Because of the high prevalence of $C$. jejuni in poultry, poultry meat is considered a major source of C. jejuni infections for humans. However, it is not known whether all poultry-associated C. jejuni strains are capable of causing disease in humans. Four different virulence properties of $C$. jejuni strains were compared between 20 poultry isolates and 24 human isolates. Strains were chosen based on their PFGE pattern to represent a heterogeneous population. The isolates were compared for their ability to invade and induce interleukin-8 (IL-8) production in T84 cells, their production of functional cytolethal distending toxin (CDT) using HEp-2 cells, and their sodium deoxycholate resistance. All four virulence factors were present among strains of human and poultry origin, with strong differences observed among strains. For invasion and IL-8 induction, no difference was observed between the two populations. However, on average, human isolates arrested more HEp-2 cells in their cell cycle than did the poultry isolates $(P=0.041)$, suggesting higher CDT production by the former. The ability to survive $16000 \mu \mathrm{g}$ sodium deoxycholate $\mathrm{ml}^{-1}$ was significantly more pronounced $(P=0.006)$ among human isolates than poultry isolates, although all strains possessed the $c m e A B C$ operon. These data suggest that all four virulence properties are widespread among $C$. jejuni isolates, but that a higher degree of bile-salt resistance and more pronounced CDT production are associated with strains causing enteritis in humans.
\end{abstract}

\section{INTRODUCTION}

Campylobacter jejuni is recognized as one of the most common causes of human gastrointestinal disease in industrialized countries, and is frequently associated with the handling and consumption of contaminated poultry meat and cross-contaminated food products (Hänninen et al., 2000; Pearson et al., 2000; Wingstrand et al., 2006). A study in the UK showed that $80 \%$ of retail poultry is contaminated with C. jejuni (Corry \& Atabay, 2001), and approximately $39 \%$ of the broiler flocks tested in a Belgian study conducted during 1998 and 2000 were positive for $C$. jejuni (Herman et al., 2003). This emphasizes the

Abbreviations: CDT, cytolethal distending toxin; IL-8, interleukin-8; TNF, tumour necrosis factor. importance of poultry as a reservoir and source of $C$. jejuni infection.

Several virulence factors are considered to be important for the induction of gastroenteritis, such as resistance to bile salts (Lin et al., 2003), invasion of epithelial cells (Russell et al., 1993) and cytolethal distending toxin (CDT) production (Konkel et al., 2001). Cell invasion could result in cellular injury, leading to reduced absorptive capacity of the intestine, whereas CDT production is important for interleukin-8 (IL-8) release by intestinal cells in vitro (Hickey et al., 1999, 2000) and thus plays an important role in the host mucosal inflammatory response.

Although poultry meat is considered an important source of $C$. jejuni infections for humans, it is not known whether all poultry-associated C. jejuni strains are capable of 
causing disease in humans. We therefore compared the capability for epithelial cell invasion, CDT production, bile-salt resistance and IL-8 induction of poultry and human isolates.

\section{METHODS}

Experimental animals. Day-of-hatch White Leghorn Chickens (Charles River Laboratories) were kept in brooder batteries and provided with food and water ad libitum. Husbandry, euthanasia methods, experimental procedures and biosafety precautions were approved by the Ethical Committee of the Faculty of Veterinary Medicine, Ghent University. Prior to use, chicks were screened for the presence of Campylobacter in the faeces. All of the chicks tested proved to be negative for Campylobacter.

Bacterial strains. In this study, 20 C. jejuni strains of poultry origin and 24 clinical isolates (kindly provided by Professor Peter Vandamme, Ghent University) were used. The choice of strains was based on their genotypic heterogeneity, which was determined by PFGE with KpnI and SmaI (Amersham Biosciences) according to the PulseNet USA protocol (http://www.cdc.gov/pulsenet/protocols/ campy_protocol.pdf). PFGE profiles were clustered with BioNumerics software (version 4.0, Applied Maths) using the Dice coefficient and the unweighted pair group method using arithmetic averages (UPGMA) clustering algorithm. PFGE clusters were defined on a similarity level of $80 \%$. All strains were routinely cultured in Nutrient Broth No. 2 (Oxoid), supplemented with Campylobacterspecific growth supplements (SR117 and SR0232, Oxoid) and 5\% lysed horse blood (E\&O Laboratories) at $42{ }^{\circ} \mathrm{C}$ under microaerobic conditions $\left(5 \% \mathrm{O}_{2}, 5 \% \mathrm{CO}_{2}, 5 \% \mathrm{H}_{2}, 85 \% \mathrm{~N}_{2}\right)$. For certain experiments, horse blood was omitted. Care was taken to pass the strains no more than five times in vitro.

Before use in virulence assays, all C. jejuni strains were passed through day-old specific pathogen-free (SPF) White Leghorn Chickens. Chicks were orally inoculated with $2 \times 10^{7}$ organisms in $0.2 \mathrm{ml} \mathrm{PBS}$. Controls were sham-inoculated with PBS alone. At $24 \mathrm{~h}$ post-inoculation, cloacal swabs were streaked on modified charcoal cefoperazone deoxycholate agar plates (mCCDA; CM0739, Oxoid) containing Campylobacter-specific growth supplements (SR0155 and SR0232, Oxoid) for $48 \mathrm{~h}$ at $42{ }^{\circ} \mathrm{C}$ under microaerobic conditions. Bacteria were collected by washing plates with $\mathrm{PBS}$, and the aliquoted suspension was stored in horse blood at $-80{ }^{\circ} \mathrm{C}$.

For the CDT assay, bacterial cell lysates were prepared by sonication. Bacterial cultures were grown in $40 \mathrm{ml}$ selective broth with $5 \%$ lysed horse blood for $19 \mathrm{~h}$ at $42{ }^{\circ} \mathrm{C}$ in a microaerobic atmosphere to a density of $5 \times 10^{7}$ c.f.u. $\mathrm{ml}^{-1}$ and harvested by centrifugation at $900 \mathrm{~g}$ for $20 \mathrm{~min}$ at $4{ }^{\circ} \mathrm{C}$. The bacteria were washed once with $3 \mathrm{ml} \mathrm{PBS}$ and resuspended in $3 \mathrm{ml}$ PBS. The pellet was sonicated on ice by eight $30 \mathrm{~s}$ pulses with an XL 2015 Sonicator (Misonix) followed by centrifugation at $6000 \mathrm{~g}$ for $10 \mathrm{~min}$ at $4{ }^{\circ} \mathrm{C}$. The supernatant was filter-sterilized by subsequent passage through 0.45 and $0.20 \mu \mathrm{m}$ pore-size filters (IWAKI, International Medical) and stored at $-80{ }^{\circ} \mathrm{C}$.

Cell lines. The HEp-2 cell line was obtained from the European Collection of Cell Cultures (ECACC). Cells were grown in Eagle's Minimum Essential Medium (EMEM; Gibco, Invitrogen) supplemented with $10 \%$ fetal calf serum, $1 \%$ glutamine, $1 \%$ non-essential amino acids and, unless stated otherwise, $100 \mathrm{U}$ penicillin $\mathrm{ml}^{-1}$ and $0.1 \mathrm{mg}$ streptomycin $\mathrm{ml}^{-1}$ (Gibco) at $37{ }^{\circ} \mathrm{C}$ in a $5 \% \mathrm{CO}_{2}$ atmosphere.

The human colon carcinoma cell line T84 (ECACC) was grown in $44 \%$ Dulbecco's Minimal Essential Medium (DMEM), $44 \%$ F-12
(Gibco), $10 \%$ fetal calf serum (Integro), $1 \%$ L-glutamine, $100 \mathrm{U}$ penicillin $\mathrm{ml}^{-1}$ and $0.1 \mathrm{mg}$ streptomycin $\mathrm{ml}^{-1}$ at $37{ }^{\circ} \mathrm{C}$ in a $5 \% \mathrm{CO}_{2}$ atmosphere.

Invasion of T84 cells by $\mathbf{C}$. jejuni strains of poultry and human origin. T84 cells were seeded in 96 -well plates at $1 \times 10^{5}$ cells per well. After $78 \mathrm{~h}$, the cells were inoculated with bacterial cells grown overnight in broth without horse blood at an m.o.i. of 200. The plates were centrifuged at $500 \mathrm{~g}$ for $10 \mathrm{~min}$ at $37{ }^{\circ} \mathrm{C}$ to enhance bacterial contact with the cell monolayer. The plates were incubated for $3 \mathrm{~h}$ at $37{ }^{\circ} \mathrm{C}$ in a $5 \% \mathrm{CO}_{2}$ atmosphere. Cells were washed with Hanks' Buffered Salt Solution (HBSS; Gibco) with $\mathrm{Ca}^{2+}$ and $\mathrm{Mg}^{2+}$ to remove non-invaded bacteria. To kill extracellular bacteria, $100 \mu \mathrm{g}$ gentamicin $\mathrm{ml}^{-1}$ (Gibco) was added to the wells. This concentration proved to be lethal for all strains tested. Plates were further incubated for $2 \mathrm{~h}$ at $37{ }^{\circ} \mathrm{C}$ in a $5 \% \mathrm{CO}_{2}$ atmosphere. Gentamicin was washed away with $\mathrm{HBSS}$ without $\mathrm{Ca}^{2+}$ and $\mathrm{Mg}^{2+}$. Intracellular bacteria were released from T84 cells with $0.25 \%$ sodium deoxycholate and titrated on mCCDA plates.

CDT production by poultry and human isolates. The CDT production of $C$. jejuni isolates was determined by the assessment of the number of HEp-2 cells blocked in the $\mathrm{G}_{2}$ phase after exposure to C. jejuni lysate (Young et al., 2000). The DNA content of HEp-2 cells incubated with the Campylobacter cell sonicates was determined quantitatively by flow cytometry. HEp- 2 cells were seeded at a density of $1 \times 10^{5}$ cells ml ${ }^{-1}$ in $25 \mathrm{ml}$ culture flasks. The cells were treated with $100 \mu \mathrm{l}$ bacterial sonicate and incubated for $72 \mathrm{~h}$ at $37^{\circ} \mathrm{C}$ with $5 \% \mathrm{CO}_{2}$. Sonicates from C. jejuni NCTC 11168 were used as a positive control (Purdy et al., 2000). Negative controls were treated likewise, but incubated with $100 \mu$ PBS. After incubation, cells were washed once with medium without antibiotics and trypsinized. The cells were collected in a Falcon tube and pelleted by centrifugation at $1000 \mathrm{~g}$ for $5 \mathrm{~min}$ at $37^{\circ} \mathrm{C}$. DNA was stained according to Chien et al. (2000). Briefly, the pellet was resuspended in $0.5 \mathrm{ml}$ staining solution (3\% PEG, $4 \mu \mathrm{g}$ propidium iodide $\mathrm{ml}^{-1}, 9 \mathrm{U}$ RNase A ml${ }^{-1}, 0.1 \%$ Triton $\mathrm{X}-100,0.0001 \% \mathrm{BSA}$, in $4 \mathrm{mM}$ sodium citrate) for $20 \mathrm{~min}$ at $37{ }^{\circ} \mathrm{C}$, followed by the addition of $0.5 \mathrm{ml}$ salt solution (3\% PEG; $4 \mu \mathrm{g}$ propidium iodide $\mathrm{ml}^{-1}, 9 \mathrm{U}$ RNase $\mathrm{A} \mathrm{m} \mathrm{m}^{-1}, 0.1 \%$ Triton X-100, $0.0001 \% \mathrm{BSA}$, in $0.4 \mathrm{M} \mathrm{NaCl}$ ) and the mixture was stored for $1.5 \mathrm{~h}$ at $4{ }^{\circ} \mathrm{C}$ in the dark. The DNA content was analysed using a FACSCalibur flow cytometer (Becton-Dickinson) and data acquisition was performed using CellQuest software. For each experiment, $10^{4}$ cells were counted.

Presence of the virB11, cdtA, cdtB and cdtC genes and the CmeABC multidrug efflux pump in human and poultry isolates of C. jejuni. The presence of the virB11 gene as a marker for the plasmid $\mathrm{pVir}$, the genes involved in CDT production $c d t A, c d t B$ and $c d t C$, and the cmeABC genes for the multidrug efflux pump, was assessed using PCR. Bacterial chromosomal DNA was isolated from an overnight liquid culture without horse blood, using the DNeasy Tissue kit (Qiagen) according to the manufacturer's instructions.

Primers (Operon Biotechnologies) used in this study and their sources are listed in Table 1. PCR was performed in a volume of $10 \mu \mathrm{l}$

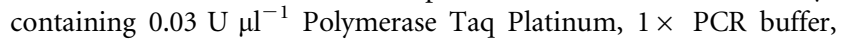
$3 \mathrm{mM} \mathrm{MgCl}_{2}$ (Invitrogen Life Technologies), $40 \mu \mathrm{M}$ dNTP (Qiagen), $0.5 \mathrm{pmol} \mu \mathrm{l}^{-1}$ primers and $20 \mathrm{ng}$ genomic DNA. Annealing temperature conditions varied according to the set of primers used. PCR products $(3 \mu \mathrm{l})$ were separated by electrophoresis in an agarose gel containing $1.5 \%$ agarose (Boehringer Mannheim) in $1 \times$ Tris-acetate/ EDTA (TAE) buffer, pH 8, and stained with ethidium bromide. Gels were visualized using Image Master VDS (Pharmacia Biotech).

Resistance to deoxycholate of $\boldsymbol{C}$. jejuni strains of poultry and human origin. MICs were determined using a modification of the 
Table 1. Primers used in this study

\begin{tabular}{|c|c|c|c|c|}
\hline $\begin{array}{l}\text { Target and annealing } \\
\text { temperature }\end{array}$ & Primer & Sequence $\left(5^{\prime}-3^{\prime}\right)$ & Size (bp) & Reference \\
\hline \multirow[t]{2}{*}{ cmeB gene, $55{ }^{\circ} \mathrm{C}$} & cmeBF & GGTACAGATCCTGATCAAGCC & 819 & Lin et al. (2002) \\
\hline & cmeBR & AGGAATAAGTGTTGCACGGAAATT & & \\
\hline \multirow[t]{2}{*}{ cmeA gene, $55^{\circ} \mathrm{C}$} & cmeAF & TTTGGATCCTTGATGGCTAAGGCAACTTTC & 781 & Lin et al. (2002) \\
\hline & cmeAR & СTCCAATTTCTTAAGCTTCGCTACC & & \\
\hline \multirow[t]{2}{*}{ cmeC gene, $53{ }^{\circ} \mathrm{C}$} & $\mathrm{cmeCF}$ & GCTTGGATCCTTATCTTGGGAAAAA & 641 & Lin et al. (2002) \\
\hline & cmeCR & TTTTTAAAGCTTTAAGGTAATTTTCTT & & \\
\hline \multirow[t]{2}{*}{ virB11 gene, $52{ }^{\circ} \mathrm{C}$} & virFW & GAACAGGAAGTGGAAAAACTAGC & 708 & Bacon et al. (2000) \\
\hline & virRV & TTCCGCATTGGGCTATATG & & \\
\hline \multirow[t]{2}{*}{$c d t A$ gene, $52{ }^{\circ} \mathrm{C}$} & cdtAFW & GGAAATTGGATTTGGGGCTATACT & 165 & Pickett et al. (1996) \\
\hline & cdtARV & ATCACAAGGATAATGGACAAT & & \\
\hline \multirow[t]{2}{*}{$c d t B$ gene, $52{ }^{\circ} \mathrm{C}$} & cdtBFW & GTTAAAATCCССТGCTATCAACCA & 495 & Pickett et al. (1996) \\
\hline & cdtBRV & GTTGGCACTTGGAATTTGCAAGGC- & & \\
\hline \multirow[t]{2}{*}{$c d t C$ gene, $52{ }^{\circ} \mathrm{C}$} & cdtCFW & TGGATGATAGCAGGGGATTTTAAC & 555 & Pickett et al. (1996) \\
\hline & cdtCRV & TTGCACATAACCAAAAGGAAG & & \\
\hline
\end{tabular}

method described by Lin et al. (2002). Briefly, Campylobacter strains were plated on plates containing twofold dilutions of sodium deoxycholate (Sigma) between 1000 and $16000 \mu \mathrm{g} \mathrm{ml}^{-1}$ in mCCDA. Overnight cultures supplemented with horse blood were spotted at a density of $1 \times 10^{4}$ bacteria, and the presence of growth was determined after $48 \mathrm{~h}$ at $42{ }^{\circ} \mathrm{C}$ under microaerobic conditions.

Induction of IL-8 production by T84 cells exposed to $C$. jejuni strains of poultry and human origin. T84 cells were seeded in 96well plates at a concentration of $1 \times 10^{5}$ cells per well. After $78 \mathrm{~h}$ the cells were inoculated with a bacterial culture grown overnight in broth without horse blood at an m.o.i. of 200. Wells were incubated with PBS as the negative control and with tumour necrosis factor (TNF) $-\alpha\left(200 \mathrm{ng} \mathrm{ml}^{-1}\right.$; Sigma) as the positive control. The plate was centrifuged at $500 \mathrm{~g}$ for $10 \mathrm{~min}$ to facilitate contact of bacteria with cells, and incubated for $24 \mathrm{~h}$ at $37{ }^{\circ} \mathrm{C}$ and $5 \% \mathrm{CO}_{2}$. Supernatant was collected and centrifuged $\left(2300 \mathrm{~g}, 10 \mathrm{~min}, 4{ }^{\circ} \mathrm{C}\right)$. The concentration of IL-8 in cell culture supernatant was measured by an ELISA (Amersham Biosciences) according to the manufacturer's instructions.

Statistical analysis. Differences in occurrence of the virB11 gene in both populations were evaluated by means of Fisher's exact test. Differences in T84 invasion, HEp-2 cell cycle arrest and IL-8 production were tested by means of one-way ANOVA. For the T84 results, $\log _{10}$ transformation was performed to obtain normally distributed data. The capacity of the different strains to survive on different concentrations of sodium deoxycholate was analysed by means of Cox proportional hazard analyses. All statistical tests were performed in SPSS 14.0.

\section{RESULTS AND DISCUSSION}

\section{Genotyping of poultry and human strains}

The aim of this study was to compare C. jejuni isolates of human origin with those of poultry origin with respect to their virulence properties. To assure genetic heterogeneity in this study, isolates were chosen on the basis of their PFGE pattern after passage through day-old chicks. The combined PFGE SmaI and KpnI profile showed that the 20 poultry isolates clustered in 17 different clusters, while the
24 human isolates clustered into 19 clusters. Both human strains and poultry isolates were spread homogeneously over the dendrogram (not shown) and none of the PFGE patterns was identical. Only two poultry and human clinical clusters showed a similarity of at least $80 \%$ with each other.

To test the genetic stability of the isolates during passage, nine poultry isolates and nine clinical isolates recovered from cloacal swabs after passage were compared by PFGE to the original isolates that were used for oral inoculation of the chick. It was confirmed that six poultry isolates recovered after passage showed $100 \%$ similarity to the original isolates by PFGE, while two isolates were slightly different ( $>90 \%$ similarity) and one isolate was somewhat more different ( $80 \%$ similarity). Four of the nine clinical isolates recovered after passage were identical to the original isolates by PFGE ( $>97 \%$ similarity), while four isolates were slightly different $(>92 \%$ similarity) and one strain was more different ( $67 \%$ similarity).

The 44 C. jejuni isolates tested in this study belonged to a large variety of genetic types, as none of the strains was identical as shown by PFGE. A certain degree of genetic instability was observed with PFGE after passage through day-old chicks for some of these strains, confirming earlier observations with passage through chick intestines (Hänninen et al., 1999).

\section{Prevalence of the virB11 gene is equal among poultry and human isolates}

Since the virB11 gene is associated with invasiveness (Bacon et al., 2000), we screened the C. jejuni collection for its presence using PCR. The virB11 gene was present equally often in the poultry strains as in the human strains $(P=0.20)$, suggesting that some poultry isolates are capable of invading the human intestine. It should be noted, however, that the prevalence of the virB11 gene was low: 
the virB11 gene was present in only six of the 24 human isolates and two of the 20 poultry isolates.

\section{C. jejuni strains from poultry and humans invade T84 cells equally}

Invasion is generally considered to be important in pathogenesis, and a higher invasive capacity is generally reported for clinical isolates than non-clinical isolates (Fauchere et al., 1986; Konkel \& Joens, 1989; Prasad et al., 1996; Tay et al., 1996). In our study, a total of 20 strains of poultry origin and 24 strains of human origin were compared with respect to their ability to invade T84 monolayers. Strains were considered invasive from $\log _{10}$ (c.f.u. $\left.\mathrm{ml}^{-1}\right)=1.0$ and above. Data from four independent experiments for the poultry isolates and three independent experiments for human clinical isolates are summarized in Table 2. All but one isolate from poultry and one isolate of human origin were invasive. There was no significant difference $(P=0.48)$ in mean invasiveness between the poultry isolates [mean \pm SEM $\log _{10}$ (c.f.u. $\left.\left.\mathrm{ml}^{-1}\right)=2.5 \pm 0.1\right]$ and the human clinical isolates [mean \pm SEM $\log _{10}$ (c.f.u. $\left.\mathrm{ml}^{-1}\right)=2.7 \pm 0.1$ ], supporting the findings of Lindblom \& Kaijser (1995). However, strong differences in invasiveness between individual strains were noticed, and a greater proportion of human isolates than poultry isolates was highly invasive with $\log _{10}$ (c.f.u. $\mathrm{ml}^{-1}$ ) $>3.5$, but this tendency was not statistically significant.

\section{Lysates from human $C$. jejuni strains arrest more HEp-2 cells in the $G_{2}$ phase than poultry isolates}

To investigate CDT production, lysates from 42 strains were tested for their ability to block the HEp-2 cell cycle. After $78 \mathrm{~h}$ incubation with bacterial sonicates or PBS, the DNA content of the cells was analysed by flow cytometry. Isolates which produced a cell cycle arrest of more than $16.9 \%$ (mean of negative controls plus $2 \times$ SEM) were considered positive. The positive control strain NCTC 11168 caused a cell cycle arrest in $56.1 \pm 3.8 \%$ of the HEp2 cells, while the negative control treated with PBS arrested $7.5 \pm 4.7 \%$ of the cells. On average, human isolates $(n=23$; mean \pm SEM $55.3 \pm 3.6 \%$ ) were able to block more cells in

Table 2. Invasion of $C$. jejuni strains of poultry and human origin in T84 monolayers, exposed to an m.o.i. of 200 for $3 \mathrm{~h}$

\begin{tabular}{|c|c|c|c|c|}
\hline \multirow[t]{2}{*}{ Type of strain } & \multicolumn{4}{|c|}{$\begin{array}{l}\text { Number }{ }^{\star} \text { (percentage of the total } \\
\text { sample) of strains with an } \\
\text { intracellular bacterial count of: }\end{array}$} \\
\hline & $<1.0$ & $1.0-2.0$ & $2.0-3.5$ & $>3.5$ \\
\hline Poultry isolates $(n=20)$ & $1(5.0)$ & $3(15.0)$ & $14(70.0)$ & $2(10.0)$ \\
\hline Human isolates $(n=24)$ & $1(4.2)$ & $2(8.3)$ & $16(66.7)$ & $5(20.8)$ \\
\hline
\end{tabular}

${ }^{\star}$ Mean $\log _{10}$ (c.f.u. $\mathrm{ml}^{-1}$ ). their cycle progression $(P=0.041)$ than the poultry isolates ( $n=19$; mean \pm SEM $43.5 \pm 4.4 \%$ ) (Table 3 ), confirming the findings on differences in toxigenicity between clinical and poultry isolates of Gilbert \& Slavik (2004) and Prasad et al. (1996). For the extreme values, no differences in proportions between the poultry isolates and the human isolates could be found: one isolate from poultry $(5.3 \%)$ and two isolates from humans $(8.7 \%)$ were considered to be negative in their ability to produce functional CDT, while four poultry isolates $(21.1 \%)$ and seven human isolates $(30.4 \%)$ arrested more than $70 \%$ of the HEp-2 cells in their cell cycle progression. The proportion of human isolates $(34.8 \%)$ which could induce between 50.0 and $70.0 \%$ of the HEp- 2 cells to remain locked in the cell cycle was greater than the equivalent proportion of poultry isolates $(5.3 \%)$.

All strains possessed the $c d t A, c d t B$ and $c d t C$ genes. It is indeed generally accepted that the $c d t$ genes are widespread amongst poultry and human isolates (Bang et al., 2003; Eyigor et al., 1999; Rozynek et al., 2005). While our data suggest an association between CDT production and clinical outcome, two clinical isolates were CDT negative, while possessing the three $c d t$ genes. The occurrence of CDT-negative strains in clinical isolates is in accordance with other observations (Abuoun et al., 2005; Bang et al., 2001; Eyigor et al., 1999), and shows that CDT might not be the sole determinant in the final clinical outcome of $C$. jejuni infection in humans.

\section{C. jejuni isolates from humans are more resistant to deoxycholate than poultry isolates}

The ability of $C$. jejuni to reach the intestinal tract is associated with gastric-acid and bile-salt tolerance, and is a prerequisite for successful colonization and thus the induction of disease. Lin et al. (2003) showed a relationship between bile-salt resistance, colonization ability and the expression of the cmeABC operon. In our study, the prevalence of the cme $A B C$ complex among the $C$. jejuni isolates was assessed using PCR. Although all 44 strains examined in this study possessed the three genes, strains were markedly different in their capacity to survive different concentrations of sodium deoxycholate. Human

Table 3. CDT-induced cell cycle arrest in the HEp-2 cell line $78 \mathrm{~h}$ after exposure to bacterial lysates of C. jejuni strains of poultry and human origin

\begin{tabular}{|c|c|c|c|c|}
\hline \multirow[t]{2}{*}{ Type of strain } & \multicolumn{4}{|c|}{$\begin{array}{l}\text { Number (percentage of the total } \\
\text { sample) of strains that induced } \\
\qquad G_{2} \text { arrest of: }\end{array}$} \\
\hline & $<16.9 \%$ & $\begin{array}{c}16.9- \\
50.0 \%\end{array}$ & $\begin{array}{c}50.0- \\
70.0 \%\end{array}$ & $>70.0 \%$ \\
\hline Poultry isolates $(n=19)$ & $1(5.3)$ & $13(68.4)$ & $1(5.3)$ & $4(21.1)$ \\
\hline Human isolates $(n=23)$ & $2(8.7)$ & $6(26.1)$ & $8(34.8)$ & $7(30.4)$ \\
\hline
\end{tabular}


isolates appeared to be significantly more resistant to bile salts than the poultry isolates $(P=0.006)$ (Fig. 1$)$, with $85 \%$ of the human strains surviving $16000 \mu \mathrm{g}$ sodium deoxycholate $\mathrm{ml}^{-1}$ compared to $54 \%$ of the poultry isolates. Increased bile-salt tolerance might thus predispose to clinical campylobacteriosis in humans.

\section{C. jejuni strains from poultry and humans induce IL-8 secretion by $\mathrm{T} 84$ monolayers to an equal extent}

Because invasion and CDT production are two mechanisms which are held to be responsible for the induction of IL-8 release (Hickey et al., 1999, 2000), we examined the capacity of the two C. jejuni populations to elicit an IL-8 response in T84 cells. Data from three independent experiments are shown in Table 4. Strains inducing more than the mean of the negative control plus $2 \times$ SEM (346.0 $\mathrm{pg} \mathrm{ml}^{-1}$ ) were considered to be positive in their ability to induce IL- 8 production. The positive TNF- $\alpha$ $\left(200 \mathrm{ng} \mathrm{ml}^{-1}\right)$ control induced a mean of $899.3 \pm 57.0 \mathrm{pg}$ IL- $8 \mathrm{ml}^{-1}$. All strains mediated IL-8 production from the T84 monolayers. Although isolates of poultry origin $\left(n=18\right.$; mean \pm SEM $\left.643.9 \pm 31.3 \mathrm{pg} \mathrm{ml}^{-1}\right)$ were not statistically different $(P=0.29)$ in their ability to induce IL-8 production from the human clinical isolates $(n=24$; mean \pm SEM $672.6 \pm 23.5 \mathrm{pg} \mathrm{ml}^{-1}$ ), it was notable that more human isolates $(66.7 \%)$ induced an IL-8 response between 600 and $700 \mathrm{pg} \mathrm{ml}^{-1}$ than did poultry isolates (33.3\%). In both C. jejuni populations, highly specialized strains exist: the lysate of the poultry strain KC 44 arrests only a small percentage of HEp-2 cells and is a poor invader, but causes the highest IL-8 response. Likewise, the human strain R-27478 induces an IL-8 response, but is a low CDT producer and invades T84 cells poorly. In contrast, two highly invasive and CDT-producing strains elicit the IL-8 response only moderately.

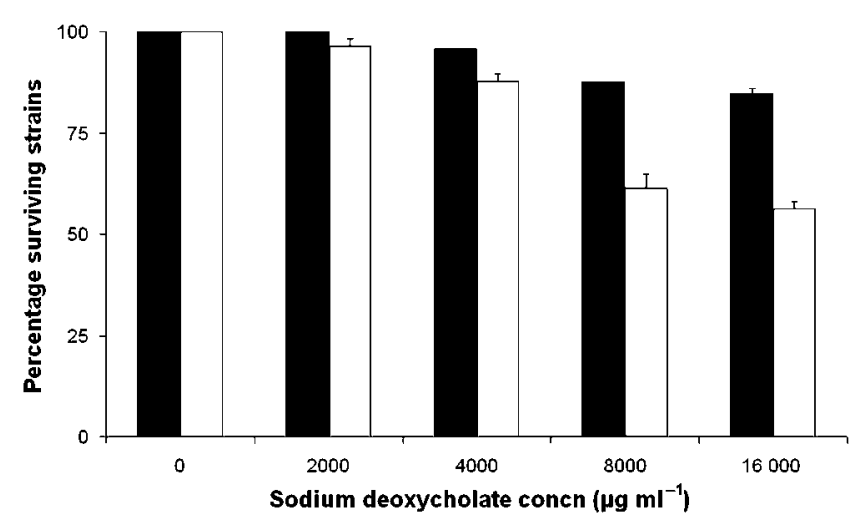

Fig. 1. Effect of sodium deoxycholate on the survival of different strains of $C$. jejuni of poultry (white bars; $n=19$ ) and human (black bars; $n=24$ ) origin. The data represent the mean \pm SEM percentage of three independent experiments.
Table 4. IL-8 induction by T84 monolayer after $24 \mathrm{~h}$ exposure to $C$. jejuni isolates of poultry and human origin at an m.o.i. of 200

\begin{tabular}{|c|c|c|c|}
\hline \multirow[t]{2}{*}{ Type of strain } & \multicolumn{3}{|c|}{$\begin{array}{l}\text { Number (percentage of the total } \\
\text { sample) of strains that induce: }\end{array}$} \\
\hline & $<600^{*}$ & $600-700^{*}$ & $>700^{*}$ \\
\hline Poultry isolates $(n=18)$ & $8(44.4)$ & $6(33.3)$ & $4(22.2)$ \\
\hline Human isolates $(n=24)$ & $3(12.5)$ & $16(66.7)$ & $5(20.8)$ \\
\hline
\end{tabular}

${ }^{\star}$ pg IL-8 $\mathrm{ml}^{-1}$.

\section{Conclusion}

In this study, no correlation between PFGE type and phenotype could be observed, nor between PFGE type and the virulence properties themselves. The appearance of low CDT-producing and poorly invading strains, which are nevertheless able to elicit an IL-8 response, raises questions about the strategies employed by $C$. jejuni to cause pathology. We conclude that based on invasiveness and the ability to induce IL- 8 production, all poultry isolates studied should be considered capable of causing human enteritis, and that enhanced CDT production and bile-salt resistance might predispose to $C$. jejuni clinical infections in humans.

\section{ACKNOWLEDGEMENTS}

This study was conducted under the Federal Public Service for Health, Food Chain Safety and Environment project (R-04/002-CAMPY). We thank Professor Peter Vandamme (Ghent University) for providing us with the human clinical C. jejuni isolates. The technical assistance of Marleen Foubert, Nathalie Van Rysselberghe, Gunter Massaer, Steven De Tollenaere and Daisy Guldentops was greatly appreciated.

\section{REFERENCES}

Abuoun, M., Manning, G., Cawthraw, S. A., Ridley, A., Ahmed, I. H., Wassenaar, T. M. \& Newell, D. G. (2005). Cytolethal distending toxin (CDT)-negative Campylobacter jejuni strains and anti-CDT neutralizing antibodies are induced during human infection but not during colonization in chickens. Infect Immun 73, 3053-3062.

Bacon, D. J., Alm, R. A., Burr, D. H., Hu, L., Kopecko, D. J., Ewing, C. P., Trust, T. J. \& Guerry, P. (2000). Involvement of a plasmid in virulence of Campylobacter jejuni 81-176. Infect Immun 68, 4384-4390.

Bang, D. D., Scheutz, F., Ahrens, P., Pedersen, K., Blom, J. \& Madsen, M. (2001). Prevalence of cytolethal distending toxin $(c d t)$ genes and CDT production in Campylobacter spp. isolated from Danish broilers. J Med Microbiol 50, 1087-1094.

Bang, D. D., Nielsen, E. M., Scheutz, F., Pedersen, K., Handberg, K. \& Madsen, M. (2003). PCR detection of seven virulence and toxin genes of Campylobacter jejuni and Campylobacter coli isolates from Danish pigs and cattle and cytolethal distending toxin production of the isolates. J Appl Microbiol 94, 1003-1014.

Chien, C. C., Taylor, N. S., Ge, Z., Schauer, D. B., Young, V. B. \& Fox, J. G. (2000). Identification of $c d t B$ homologues and cytolethal 
distending toxin activity in enterohepatic Helicobacter spp. J Med Microbiol 49, 525-534.

Corry, J. E. \& Atabay, H. I. (2001). Poultry as a source of Campylobacter and related organisms. Symp Ser Soc Appl Microbiol 30, 96S-114S.

Eyigor, A., Dawson, K. A., Langlois, B. E. \& Pickett, C. L. (1999). Detection of cytolethal distending toxin activity and $c d t$ genes in Campylobacter spp. isolated from chicken carcasses. Appl Environ Microbiol 65, 1501-1505.

Fauchere, J. L., Rosenau, A., Veron, M., Moyen, E. N., Richard, S. \& Pfister, A. (1986). Association with HeLa cells of Campylobacter jejuni and Campylobacter coli isolated from human feces. Infect Immun 54, 283-287.

Gilbert, C. \& Slavik, M. (2004). Determination of toxicity of Campylobacter jejuni isolated from humans and from poultry carcasses acquired at various stages of production. J Appl Microbiol 97, 347-353.

Hänninen, M. L., Hakkinen, M. \& Rautelin, H. (1999). Stability of related human and chicken Campylobacter jejuni genotypes after passage through chick intestine studied by pulsed-field gel electrophoresis. Appl Environ Microbiol 65, 2272-2275.

Hänninen, M. L., Perko-Makela, P., Pitkala, A. \& Rautelin, H. (2000). A three-year study of Campylobacter jejuni genotypes in humans with domestically acquired infections and in chicken samples from the Helsinki area. J Clin Microbiol 38, 1998-2000.

Herman, L., Heyndrickx, M., Grijspeerdt, K., Vandekerchove, D., Rollier, I. \& De Zutter, L. (2003). Routes for Campylobacter contamination of poultry meat: epidemiological study from hatchery to slaughterhouse. Epidemiol Infect 131, 1169-1180.

Hickey, T. E., Baqar, S., Bourgeois, A. L., Ewing, C. P. \& Guerry, P. (1999). Campylobacter jejuni-stimulated secretion of interleukin- 8 by INT407 cells. Infect Immun 67, 88-93.

Hickey, T. E., McVeigh, A. L., Scott, D. A., Michielutti, R. E., Bixby, A., Carroll, S. A., Bourgeois, A. L. \& Guerry, P. (2000). Campylobacter jejuni cytolethal distending toxin mediates release of interleukin- 8 from intestinal epithelial cells. Infect Immun 68, 6535-6541.

Konkel, M. E. \& Joens, L. A. (1989). Adhesion to and invasion of HEp2 cells by Campylobacter spp. Infect Immun 57, 2984-2990.

Konkel, M. E., Monteville, M. R., Rivera-Amill, V. \& Joens, L. A. (2001). The pathogenesis of Campylobacter jejuni-mediated enteritis. Curr Issues Intest Microbiol 2, 55-71.
Lin, J., Michel, L. O. \& Zhang, Q. (2002). CmeABC functions as a multidrug efflux system in Campylobacter jejuni. Antimicrob Agents Chemother 46, 2124-2131.

Lin, J., Sahin, O., Michel, L. O. \& Zhang, Q. (2003). Critical role of multidrug efflux pump CmeABC in bile resistance and in vivo colonization of Campylobacter jejuni. Infect Immun 71, 4250-4259.

Lindblom, G. B. \& Kaijser, B. (1995). In vitro studies of Campylobacter jejuni/coli strains from hens and humans regarding adherence, invasiveness, and toxigenicity. Avian Dis 39, 718-722.

Pearson, A. D., Greenwood, M. H., Donaldson, J., Healing, T. D., Jones, D. M., Shahamat, M., Feltham, R. K. \& Colwell, R. R. (2000). Continuous source outbreak of campylobacteriosis traced to chicken. J Food Prot 63, 309-314.

Pickett, C. L., Pesci, E. C., Cottle, D. L., Russell, G., Erdem, A. N. \& Zeytin, H. (1996). Prevalence of cytolethal distending toxin production in Campylobacter jejuni and relatedness of Campylobacter sp. $c d t B$ gene. Infect Immun 64, 2070-2078.

Prasad, K. N., Dhole, T. N. \& Ayyagari, A. (1996). Adherence, invasion and cytotoxin assay of Campylobacter jejuni in HeLa and HEp-2 cells. J Diarrhoeal Dis Res 14, 255-259.

Purdy, D., Buswell, C. M., Hodgson, A. E., McAlpine, K., Henderson, I. \& Leach, S. A. (2000). Characterisation of cytolethal distending toxin (CDT) mutants of Campylobacter jejuni. J Med Microbiol 49, 473-479.

Rozynek, E., Dzierzanowska-Fangrat, K., Jozwiak, P., Popowski, J., Korsak, D. \& Dzierzanowska, D. (2005). Prevalence of potential virulence markers in Polish Campylobacter jejuni and Campylobacter coli isolates obtained from hospitalized children and from chicken carcasses. J Med Microbiol 54, 615-619.

Russell, R. G., O’Donnoghue, M., Blake, D. C., Jr, Zulty, J. \& DeTolla, L. J. (1993). Early colonic damage and invasion of Campylobacter jejuni in experimentally challenged infant Macaca mulatta. J Infect Dis 168, 210-215.

Tay, S. T., Devi, S., Puthucheary, S. \& Kautner, I. (1996). In vitro demonstration of the invasive ability of campylobacters. Zentralbl Bakteriol 283, 306-313.

Wingstrand, A., Neimann, J., Engberg, J., Nielsen, E. M., GernerSmidt, P., Wegener, H. C. \& Molbak, K. (2006). Fresh chicken as main risk factor for campylobacteriosis, Denmark. Emerg Infect Dis 12, 280-285.

Young, V. B., Knox, K. A. \& Schauer, D. B. (2000). Cytolethal distending toxin sequence and activity in the enterohepatic pathogen Helicobacter hepaticus. Infect Immun 68, 184-191. 